Revue des patrimoines

46 | 2022

Le patrimoine de la Justice

\title{
Le patrimoine de la justice à Périgueux (Dordogne)
}

The heritage of justice in Périgueux (Dordogne department)

\section{Martine Balout}

\section{(2) OpenEdition}

Journals

Édition électronique

URL : https://journals.openedition.org/insitu/34105

DOI : $10.4000 /$ insitu. 34105

ISSN : 1630-7305

\section{Éditeur}

Ministère de la Culture

\section{Référence électronique}

Martine Balout, « Le patrimoine de la justice à Périgueux (Dordogne) », In Situ [En ligne], 46 | 2022, mis en ligne le 16 janvier 2022, consulté le 03 février 2022. URL : http://journals.openedition.org/insitu/ 34105 ; DOI : https://doi.org/10.4000/insitu.34105

Ce document a été généré automatiquement le 3 février 2022

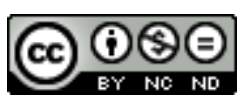

In Situ Revues des patrimoines est mis à disposition selon les termes de la licence Creative Commons Attribution - Pas d'Utilisation Commerciale - Pas de Modification 4.0 International. 


\section{Le patrimoine de la justice à Périgueux (Dordogne)}

The heritage of justice in Périgueux (Dordogne department)

\section{Martine Balout}

\section{La justice à Périgueux à l'époque médiévale}

1 La ville de Périgueux (Dordogne) comporte deux centres distincts : la Cité, Civitas, qui occupe l'emplacement de l'ancienne ville antique de Vesunna," devenue centre administratif, siège du diocèse ecclésiastique et le Bourg, Burgus, ou ville du Puy-SaintFront, au pied de la grande abbatiale, sur la colline du même nom ${ }^{1}$.

2 La maison du Consulat [fig. 1], cœur et cerveau de la vie municipale, fut édifiée ou aménagée après le traité d'Union entre les deux groupes de population, la Cité et le Puy, de 1240. Un accord spécifie que cette «maison » doit être au Puy-Saint-Front; elle est construite à cheval sur la limite de deux paroisses, Saint-Front et Saint-Silain, pour n'en privilégier aucune. L'acte d'Union entre la Cité et le Puy-Saint-Front stipulait que l'application de la haute justice était dévolue au consulat. Malgré cet accord, plusieurs conflits éclatèrent autour de l'exercice de la justice de sang ${ }^{2}$. 
Figure 1

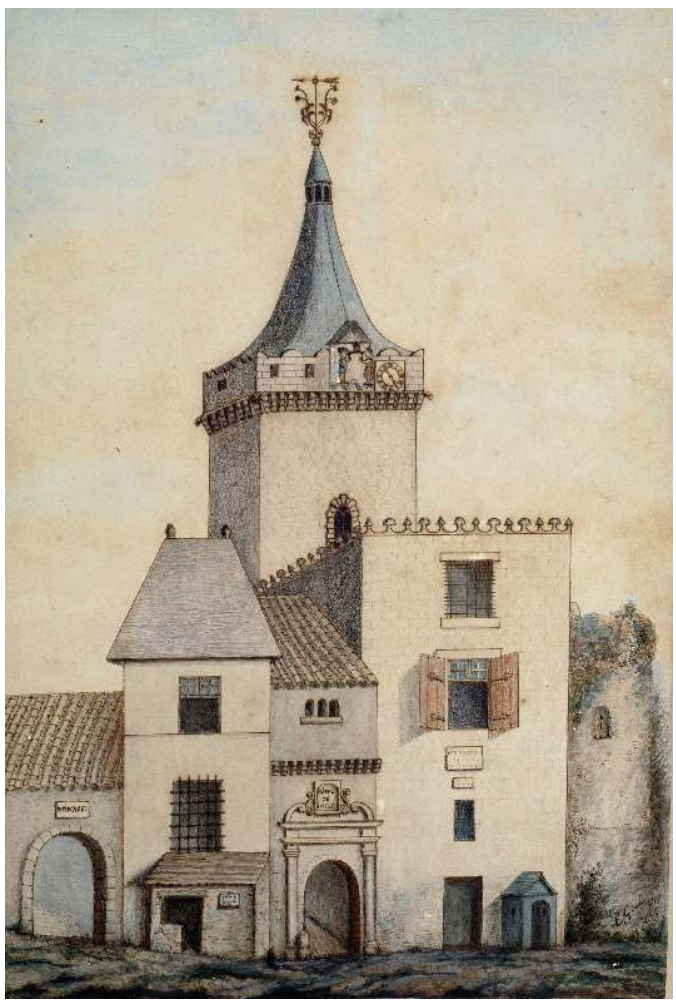

La maison du Consulat, à l'emplacement des halles, place du Coderc, Edouard Galy, dessin non daté, conservé au musée d'Art et d'Archéologie du Périgord (Inv. B.266).

Reproduction musée d'Art et d'Archéologie du Périgord.

Un conflit opposait le consulat qui détenait la justice criminelle acensée par le comte moyennant rente, à deux instances judiciaires, celle du cellérier qui exerçait la justice civile dans le cadre du paréage entre le roi et le chapitre de Saint-Front et celle du viguier et du chapitre qui traitait les affaires criminelles qui n'étaient pas de la compétence du comte.

Dès le milieu du XII siècle, la communauté des bourgeois du Puy-Saint-Front possédait un sceau aux contrats. Les consuls, chargés d'assurer l'exécution des actes passés sous ce sceau, exerçaient à cette occasion une justice civile encore peu importante.

Pour la répression des crimes et des délits, le Bourg était encore restreint à la paroisse de Saint-Front, et elle incombait donc à cette époque aux officiers du chapitre, propriétaire du domaine sur lequel la ville s'était développée. Celle-ci grandissant peu à peu, le pouvoir consulaire s'y affermissait en s'attaquant à la justice abbatiale. Il commençait à s'attribuer une juridiction pénale qui s'exerçait, dans certains cas, jusque dans la paroisse de Saint-Front, pendant qu'il acquérait une compétence exclusive sur les nouveaux centres qui successivement venaient se grouper autour du noyau primitif.

Avant 1240, le comte de Périgord donna à cens à la municipalité la justice criminelle qu'il détenait au Puy-Saint-Front moyennant une rente annuelle de vingt livres. Ainsi fut constituée peu à peu la justice consulaire. Les maires et consuls l'exerçaient en personne ou par leurs officiers. Les audiences étaient publiques et se tenaient dans l'hôtel du Consulat, à la fois dans la paroisse de Saint-Silain et dans celle de Saint-Front. 
7 Il ne semble pas que les maires et consuls jugeaient eux-mêmes : ils déléguaient leurs pouvoirs au juge de la Ville. La municipalité employait aussi des procureurs d'après l'enquête de 1332 ; un " procurator villarum Podii Sancti Frontonis et Civitatis » est cité dans un acte du 23 janvier 1314.

8 Le ressort était fort étendu. Après les interventions de la Ville devant le Parlement de Paris, en 1342, les maires et consuls avaient tous les droits de justice dans dixsept paroisses de la ville et banlieue. La justice consulaire avait été imposée à la Cité par le traité d'Union [fig. 2].

Figure 2

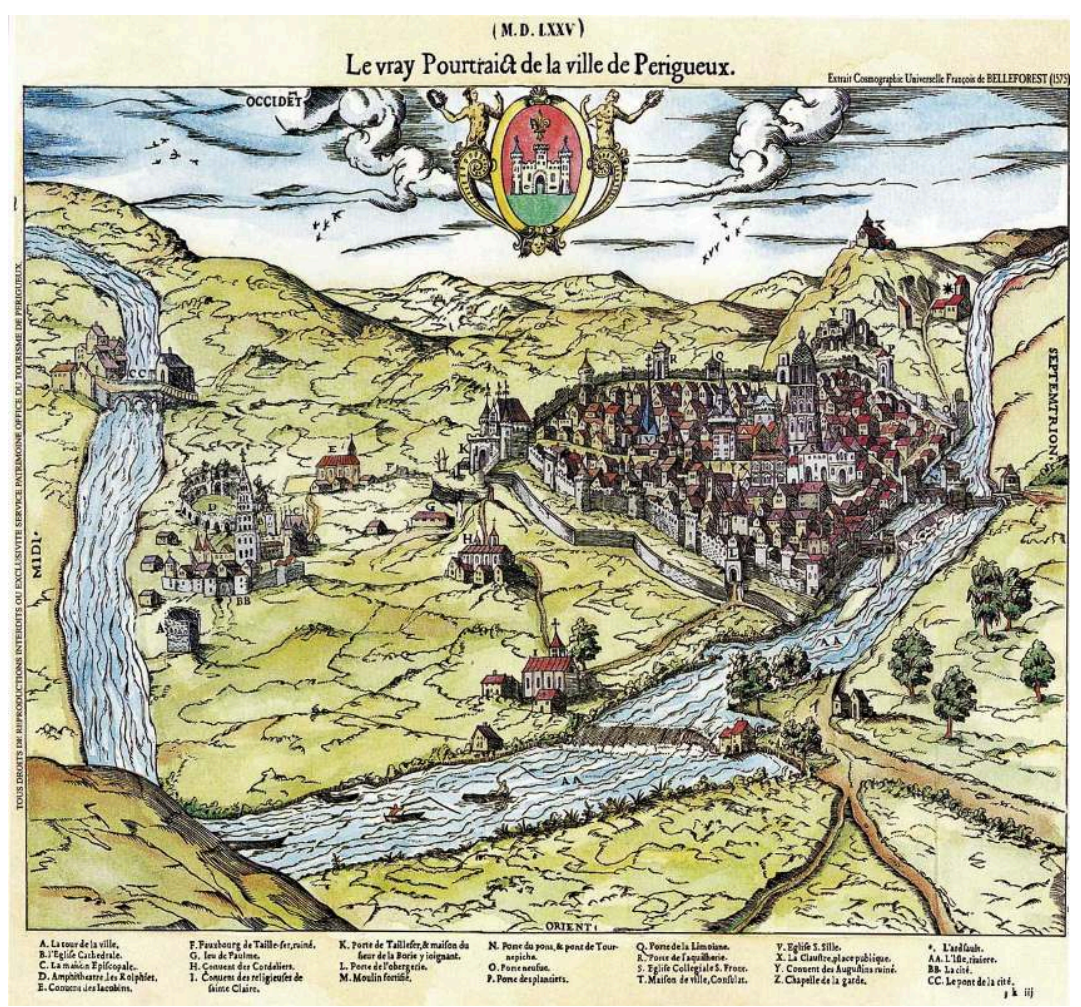

Le vrai Pourtraict de la ville de Périgueux, extrait de la Cosmographie universelle de tout le monde, François de Belleforest 1575.

Reproduction archives départementales de la Dordogne.

Elle en fut si humiliée qu'elle essaya à maintes reprises de se rebeller. En 1288, par exemple, les deux consuls de la Cité ne s'estimèrent plus liés par ce traité, renouvelé en 1269. Il avait été alors convenu que la maison commune serait toujours au Puy-SaintFront et que les deux consuls y jugeraient les litiges survenus entre bourgeois et citoyens. Les deux consuls de la Cité refusèrent d'aller traiter ces affaires au consulat. Le roi condamna leur prétention et les citoyens durent se soumettre. La cour consulaire avait, au civil, une compétence dont atteste un document conservé aux archives communales. Il s'agit d'un plumitif des audiences de cette cour consulaire pendant l'année 1328-1329. Il fournit, avec l'énumération des affaires inscrites au rôle, les plus précieux renseignements sur cette fonction de la justice communale. Le juge de la ville avait seul autorité, semble-t-il, pour prononcer en matière civile sur les questions nées dans la ville et banlieue, hors la paroisse de Saint-Front. Sur ce territoire, domaine abbatial, un officier capitulaire, le cellérier, partageait avec la cour consulaire les 
affaires civiles. Les bornes n'étant pas exactement fixées entre ces deux juridictions, cela favorisait les empiétements et perpétuait les conflits ${ }^{3}$.

En matière pénale, la compétence de la cour consulaire s'organisait séparément entre les deux noyaux de ville. Le vigier du chapitre traitait des affaires que l'on nommerait aujourd'hui correctionnelles. Il s'agissait d'une justice pénale de première instance qui s'exerçait sur les deux paroisses de Saint-Front et de Saint-Silain. La compétence paraît être analogue à celle d'un juge de paix actuel. La maison du Viguier, symbolisant la puissance temporelle des chanoines opposée à celle du consulat, se situait 3 rue du Calvaire, aujourd'hui intégrée à l'ensemble scolaire Saint-Front-La Miséricorde.

11 La justice royale s'exerçait à Périgueux à travers une justice de première instance et une juridiction d'appel. Le représentant permanent du roi, dépositaire régional de ses droits judiciaires, était le sénéchal du Périgord et du Quercy. Ce dernier ne résidait pas à Périgueux de façon permanente; il rendait la justice dans l'hôtel du Consulat. En première instance, le sénéchal connaissait des causes qui, tant au civil qu'au criminel, relevaient directement du roi. Les cas royaux ne furent jamais exactement fixés.

La justice comtale était rendue par le prévôt, un officier en délégation d'exercice. La compétence du prévôt comtal s'étendait naturellement aux hommes et au domaine que les comtes possédaient à Périgueux. Les agents de la justice consulaire procédaient euxmêmes à l'exécution de ces sentences. La cour communale avait sa prison attenante, à l'hôtel du Consulat, logée dans une tour. Il y avait en outre, à la Cité, une fosse où l'on gardait jusqu'au matin les malfaiteurs qui avaient été arrêtés nuitamment dans cette partie de ville. Dès que les portes s'ouvraient, les consuls de la Cité étaient tenus de conduire ou de faire conduire ces malfaiteurs au Consulat, dans la prison commune, sous peine d'amende ${ }^{4}$.

\section{Supplices et lieux d'exécution}

Les supplices étaient abondants et variés. Les « criminels étaient, par l'ordre des maires et consuls, questionnés, liés, étirés, mutilés ou fouettés, selon l'exigence de la justice, condamnés à être pendus, noyés, enterrés vivants ou brûlés vifs. Ces exécutions se déroulaient dans la paroisse de Saint-Front ainsi que dans d'autres lieux de la ville ${ }^{5}$ ».

Un procès-verbal de 1332 indique que la municipalité détenait le droit de haute justice et possédait des fourches patibulaires dressées sur la colline d' "Écornebœuf », une des sept collines de Périgueux, bordée par des voies de communication, au sud de l'Isle, alors que la ville double se développait au nord de la rivière. Lieu d'exécution dédié à la pendaison, les furcas patibulares étaient également le lieu d'exposition des corps et à d'inhumation pour les criminels et condamnés à mort. Les cadavres de condamnés à mort et de criminels morts dans les prisons du Consulat pouvaient y être amenés et mis en terre dans des fosses. Depuis le tribunal ou la geôle consulaire, le parcours judiciaire public empruntait un chemin bordé d'établissements religieux, autant de stations pour ceux qui désiraient se confesser et recevoir l'absolution. La colline abrita les fourches jusqu'au $\mathrm{xv}^{\mathrm{e}}$ siècle. À partir de cette période, selon les archives, "les exécutions criminelles prennent un caractère moins cruel. Par suite d'une meilleure organisation des pouvoirs publics, les moyens de répression s'étaient multipliés et il devenait moins nécessaire de chercher à prévenir les crimes en frappant l'imagination populaire par l'appareil terrifiant des supplices ${ }^{6} »$. 
$\mathrm{Au}$ XIV ${ }^{e}$ siècle, l'espace public dédié était la place de la Clautre [fig. 3] pour la justice consulaire, ainsi que le lieu d'exécution des autres peines mineures, comme l'amende honorable, le blâme, le fouet ou les verges. On y infligeait en outre le supplice de la roue, on y brûlait le cadavre de quelques pendus, on y pratiquait la flétrissure au fer rouge, la peine du carcan. La ville possédait plusieurs piloris (espillori), mentionnés dans les registres des comptes consulaires pour diverses réparations entre 1314 et la Révolution. C'étaient des ouvrages de charpente chevillés de fer; étant exposés aux intempéries, ils firent souvent l'objet de restaurations ou consolidations. Un pilori (pilare) épiscopal est également attesté sur la place principale de la Cité, devant la première cathédrale Saint-Étienne.

Figure 3

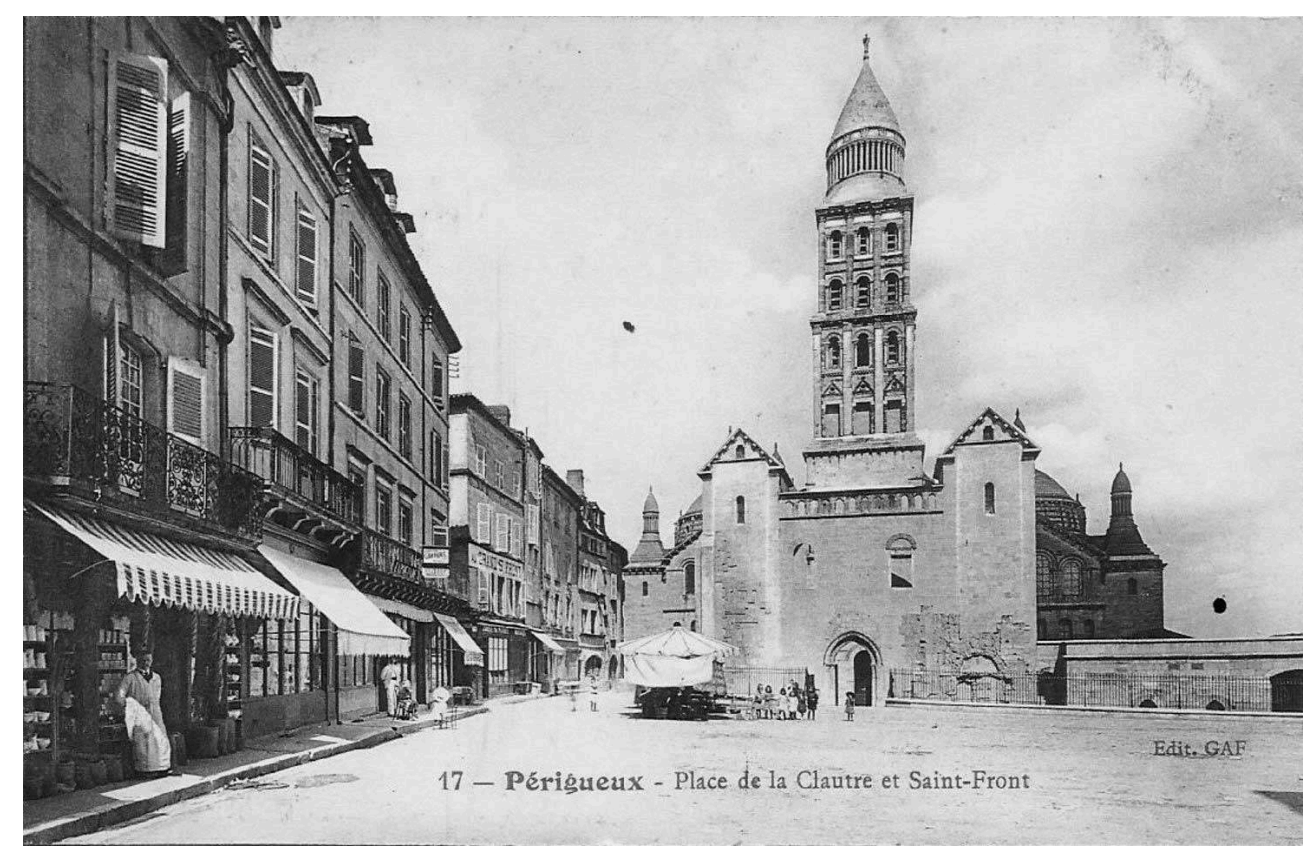

La place de la Clautre devant la cathédrale Saint-Front, vers 1920, collection particulière.

Reproduction Martine Balout.

Le pilori de la place de la Clautre fut déplacé au cimetière Saint-Silain en 1767 par arrêt du parlement de Bordeaux. Un autre pilori était présent sur la place du Coderc, à côté du Consulat. On y annonça une décapitation en 1566; il fut supprimé en 1793 pour planter un arbre de la Liberté.

Sous la Terreur, entre 1793 et 1794, la guillotine était installée place de la Clautre. Vingt-et-une exécutions y sont recensées. Au début du XIX siècle, le triste spectacle des exécutions criminelles était réservé à la place du Coderc sur laquelle se trouvaient l'hôtel de ville et la cour de justice. Cet état de choses se poursuivit jusqu'en 1840, lorsque, par une pétition, de nombreux habitants demandèrent que les peines au carcan prononcées par la cour d'assises, cessent d'y être exécutées. Le maire désigna, par arrêté du 12 janvier 1840, la place du foirail, dite de Francheville, qui servait alors de marché aux porcs, pour les exécutions capitales. Pierre Delcouderc, âgé de vingtsept ans, rendu célèbre par ses crimes, y fut exécuté le 16 avril 1845 ; un moulage de sa tête décapitée [fig. 4] est conservée au musée d'Art et d'Archéologie du Périgord. Il avait tué un ancien soldat en l'égorgeant et lui fracassant la tête, décapité un autre 
homme avec un rasoir et tenté de tuer un couple de cabaretiers. En 1846, la "Veuve », nom donné alors à cet instrument meurtrier ${ }^{7}$, fut dressée devant la prison actuelle, place Belleyme. Firmin Cipière qui avait tué ses anciens maitres, fut le dernier à y être guillotiné, le 29 juillet 1930. L'exécution du dernier condamné à mort par la cour d'assises de la Dordogne, Henri Pons, en 1958, eut lieu à Bordeaux en 1961, au fort du Hầ .

Figure 4

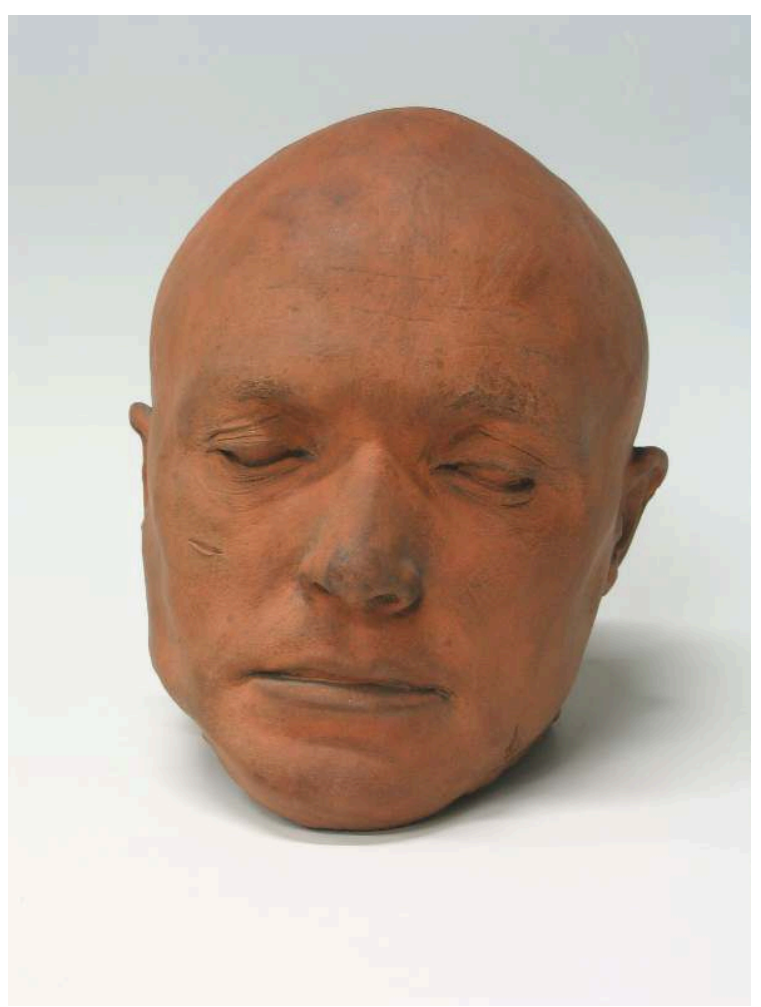

Moulage de la tête de Pierre Delcouderc, exécuté place Francheville en 1845. Moulage conservé au musée d'Art et d'Archéologie du Périgord, 2008.

(c) Isabelle Maleyre (musée d'Art et d'Archéologie du Périgord).

\section{Institutions judiciaires royales}

$18 \mathrm{Au} \mathrm{xVI}{ }^{e}$ siècle, Périgueux bénéficia de nouvelles institutions judiciaires royales, avec la création, par le roi Henri II, des présidiaux, tribunaux intermédiaires destinés à raccourcir les procès que les parlements ne parvenaient pas à examiner et à soulager ces cours souveraines des affaires peu importantes.

19 Le présidial de Périgueux fut établi par édit du 24 octobre 1552 [fig. 5]. Il jugeait sans appel quand la somme en litige ne dépassait pas 250 livres du capital ou 10 livres de rentes; en 1774, la somme fut étendue à 2000 livres. Sa compétence était analogue à celle des tribunaux d'instance actuels. Cette cour présidiale faisait double cour avec la sénéchaussée. Elle tenait séance dans la salle haute du Consulat puis au couvent des Augustins, avant de revenir au Consulat. 


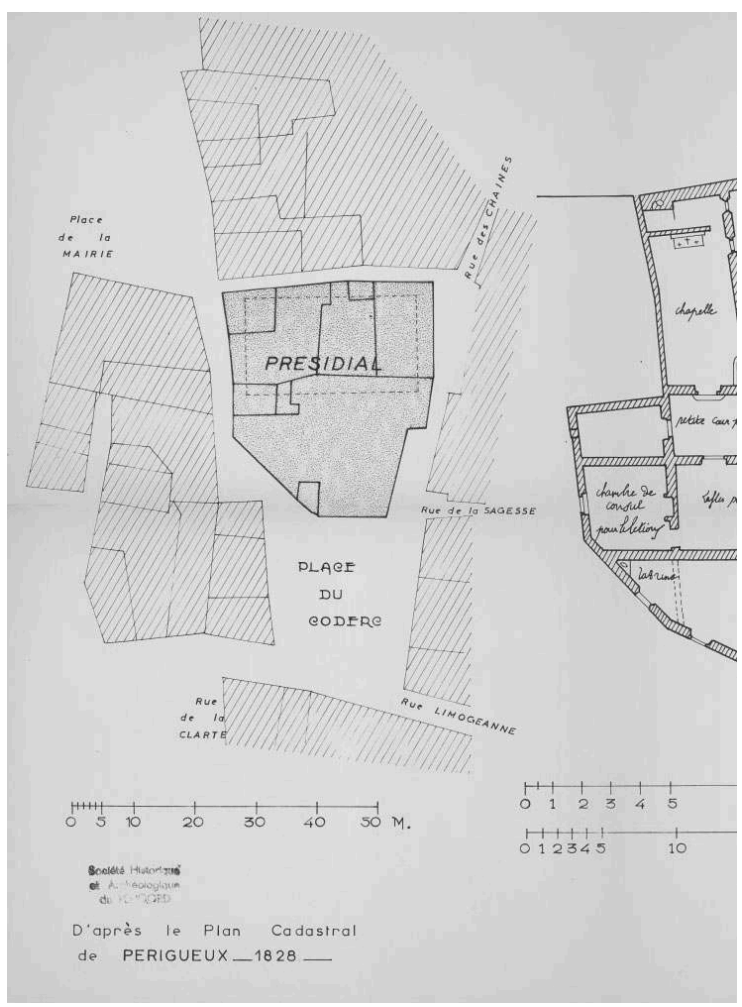

Emplacement du présidial, place du Coderc, d'après le plan cadastral de 1828. Relevés Guy Ponceau, 1962, conservés aux archives départementales de la Dordogne (2J 1302).

Reproduction archives départementales de la Dordogne.

À côté de cette juridiction à la fois criminelle et civile subsistait la cour sénéchale. Les deux tribunaux ne se distinguaient que par l'importance des affaires soumises à leur juridiction et le nombre de magistrats qui y siégeaient. Les Périgourdins, humiliés de voir Bordeaux s'enrichir à leur détriment ne cessaient de protester contre l'injustice dont ils s'estimaient victimes. Le parlement de la ville rivale vint cependant siéger à Périgueux pour échapper à la peste en 1464 et 1518.

21 Le présidial dut renoncer à son ambition d'être élevé au rang de cour souveraine. Pendant deux siècles, il continua à ne juger qu'en première instance et à voir les appels de ses sentences portés devant le parlement de Bordeaux. La dernière tentative pour rendre à Périgueux son rang de premier ordre est due à Louis XVI. L'ordonnance royale du 8 mai 1788 qui instituait en France quarante-sept grands bailliages en créa quatre dans le ressort du parlement de Bordeaux. Périgueux devint siège d'une de ces nouvelles juridictions, qui devançaient la création des cours d'appel. Le présidial de Périgueux fut alors appelé à juger en dernier ressort non seulement toutes les contestations civiles jusqu'à 20000 livres mais encore toutes les affaires criminelles, sauf celles concernant les ecclésiastiques, gentilshommes et autres privilégiés. L'extension de la compétence du tribunal suscita le mécontentement du parlement de Bordeaux. Le 22 août 1788 , le présidial prit le titre et la forme du grand bailliage de Périgueux, auquel il dut renoncer par suite de la déclaration royale du 28 septembre de la même année suspendant les bailliages. Un parlement éphémère en Périgord! Cette extension de compétence et d'autorité correspondait aux aspirations aristocratiques de l'oligarchie périgourdine. 


\section{La cour souveraine des aides}

Henri II crut réparer les torts faits à la communauté de Périgueux, dont les nobles bourgeois exemptés de tailles et ne relevaient que de la Couronne, en instituant deux ans après la création du présidial une cour souveraine des aides par les édits de mars et juin 1554, ainsi qu'il l'avait fait dans plusieurs villes importantes du royaume.

23

Cette cour traitait de toutes les affaires civiles et criminelles qui s'élevaient à propos des aides, des gabelles et des tailles. Elle rappela sa supériorité territoriale en étendant son autorité sur les généralités de Guyenne, de Poitou et d'Auvergne qui englobaient presque toute l'ancienne Aquitaine. Créer de nouvelles charges était un moyen de remplir les coffres du royaume que les guerres contre Charles Quint avaient épuisées. Bordeaux et Périgueux se l'étaient disputée, Rochefort avait rivalisé d'habilité et d'intrigues. Bordeaux avait offert 50000 écus mais faute d'argent comptant, c'est Périgueux qui l'avait obtenue pour 10000 écus seulement, payés comptant et à découvert, un honneur bien coûteux [fig. 6]. Le 28 mai 1554, la municipalité avait été obligée de vendre à deux bourgeois, marchands de Limoges, pour 2500 écus "l'émolument du poids de la chair lui appartenant ", afin de payer son acquisition, et en 1568, elle était obligée d'avouer «ne plus posséder aucuns deniers communs ou patrimoniaux, ayant dû aliéner ceux qu'elle avait autrefois, et même recourir à une imposition pour s'acquitter de ses engagements envers le Roi, lors de l'établissement dans ces murs de cette Cour ${ }^{9}$ » qui peu après, fut transférée à Bordeaux et unie à la chambre des requêtes. Les oppositions des cours de Paris et de Montpellier, ainsi que les plaintes de plaideurs éloignés aboutirent à la suppression de la cour des aides en 1771. 


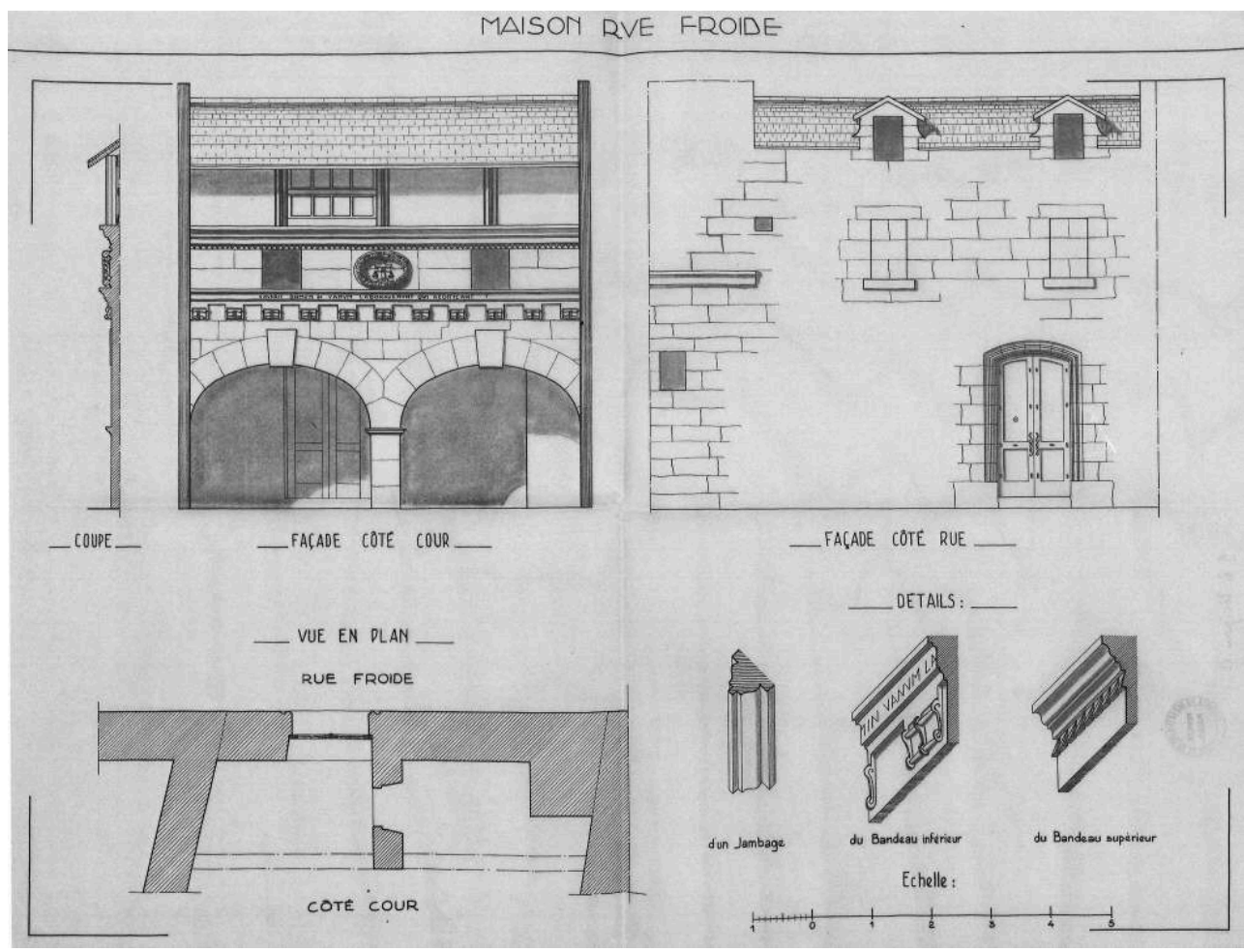

La cour des aides de Périgueux. Détails architecturaux. Relevés Guy Ponceau, 1962, conservés aux archives départementales de la Dordogne (9Fi Périgueux 62 1).

Reproduction archives départementales de la Dordogne.

Parmi les vingt-deux officiers-magistrats qui composaient la cour des aides de Périgueux inaugurée très solennellement le 16 décembre 1554, siégeait Pierre Eyquem, seigneur de Montaigne, père de Michel de Montaigne. Le célèbre écrivain succéda à son père en 1555, à l'âge de 24 ans. Il suivit la cour à Bordeaux, où il fit la connaissance d'Étienne de La Boétie, le plus jeune des conseillers, qui devint pour lui un ami et un frère. Les deux institutions étaient logées à la sénéchaussée, dans le bâtiment du Consulat, mais la salle haute du Consulat n'était pas assez grande pour suffire aux réunions des deux cours. La cour des aides fut transférée au couvent des Jacobins, sur le site actuel du quartier Sainte-Ursule, à l'extérieur de l'ancienne ville remparée puis vraisemblablement dans la demeure de Denis d'Aytz, seigneur de Meymy, en bordure de deux voies : 4 rue du Cimetière Saint-Silain et 21 rue Bonnaventure.

Cet édifice peut être identifié comme ayant été le siège d'une institution judiciaire en raison d'un médaillon en bas-relief où sont réunies, dans une couronne ovale de feuillages de chêne liés par des rubans, la croix du Christ et les balances de la Justice. La devise du roi de France Charles IX (1560-1574), «Pietate et justitia " (Avec piété et justice) [fig. 7] est gravée de part et d'autre et sous les bras de la croix. 


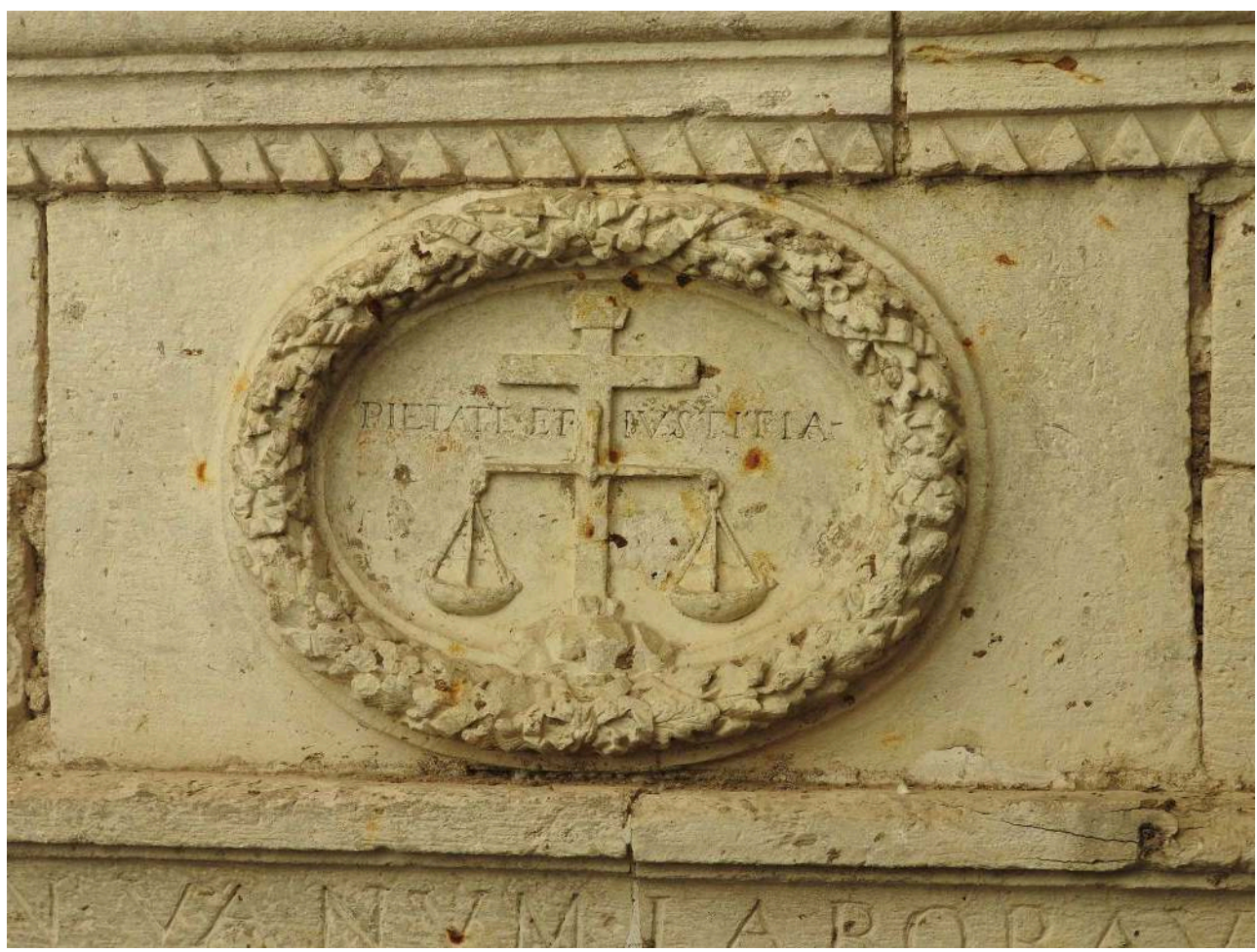

Décor et inscription de la galerie de la cour des aides, 21 rue Berthe-Bonnaventure.

(c) Valentin Coupri (service Ville d'art et d'histoire de la Ville de Périgueux).

La cour des aides revint au Consulat lorsque les magistrats de la cour présidiale décidèrent de tenir leurs séances dans le vieux couvent des Augustins, aujourd'hui musée d'Art et d'Archéologie. Puis la municipalité tenta d'acquérir deux maisons mitoyennes de l'hôtel du Consulat pour y loger la cour des aides et le présidial. La cour fut supprimée en 1557.

D'après une requête de 1777, le présidial occupait la maison de Beaumont, dans le quartier Saint-Silain, et l'on envisageait à nouveau d'acheter deux maisons pour loger le présidial et la sénéchaussée : les officiers, qui étaient alors au nombre de vingt-cinq titulaires, rappelèrent que le bâtiment devait aussi pouvoir accueillir les avocats et leurs clients, le procureur et le public.

\section{Chambre de justice}

Après les troubles des guerres de Religion et la paix du Fleix (Dordogne, 26 novembre 1580), le roi Henri III, pour mettre un terme aux nombreuses exactions commises, envoya en Guyenne une délégation de magistrats du Parlement de Paris qui tinrent à tour de rôle leurs assises à Bordeaux, à Agen, à Périgueux et à Saintes. Cette chambre siégea à Périgueux, dans la salle de l'hôtel de ville, du 27 juin 1583 au 10 janvier 1584 . Cette mesure était absolument nécessaire, les magistrats du pays ayant été trop directement mêlés aux événements pour conserver une autorité suffisante dans la province et y rendre bonne justice. Cette chambre itinérante avait toutes les compétences nécessaires pour en imposer aux populations et faire respecter ses décisions. 
Après le départ de la cour des aides et de la chambre de justice, la cour présidiale occupa à nouveau la chambre haute du Consulat.

En 1776, les chambres qu'elle avait coutume d'utiliser étaient dans un tel état de délabrement qu'il était impossible d'y siéger et qu'elle se retira sine die, laissant au roi le soin d'y remédier.

On pensa à s'installer dans quelques maisons particulières mais aucune ne convenant, il fut question d'établir un palais de justice, sans que ce projet ne soit réalisé.

Au mois de décembre 1776, après de nombreuses recherches, la cour fut priée d'aller s'établir provisoirement dans l'ancien collège des Jésuites (actuel centre culturel François-Mitterrand), place Hoche, où elle se rendit de mauvaise grâce. Un procèsverbal fut dressé pour signaler les inconvénients de ce séjour dans cette demeure «à l'extrémité de la ville et d'un accès difficile, puis la seule disponible, sert journellement à la récréation des pensionnaires ${ }^{10} \ldots$ ». Cette installation défectueuse et censée provisoire dura des années. La cour présidiale siègea au collège jusqu'à sa suppression en 1804. À cette date, elle devint tribunal civil et occupa un immeuble, 10 place du Coderc [fig. 8]. Dès 1792, les archives mentionnent un tribunal de commerce qui tenait ses audiences au Consulat, puis dans l'ancien lieu de justice, place du Coderc $^{11}$.

\section{Figure 8}

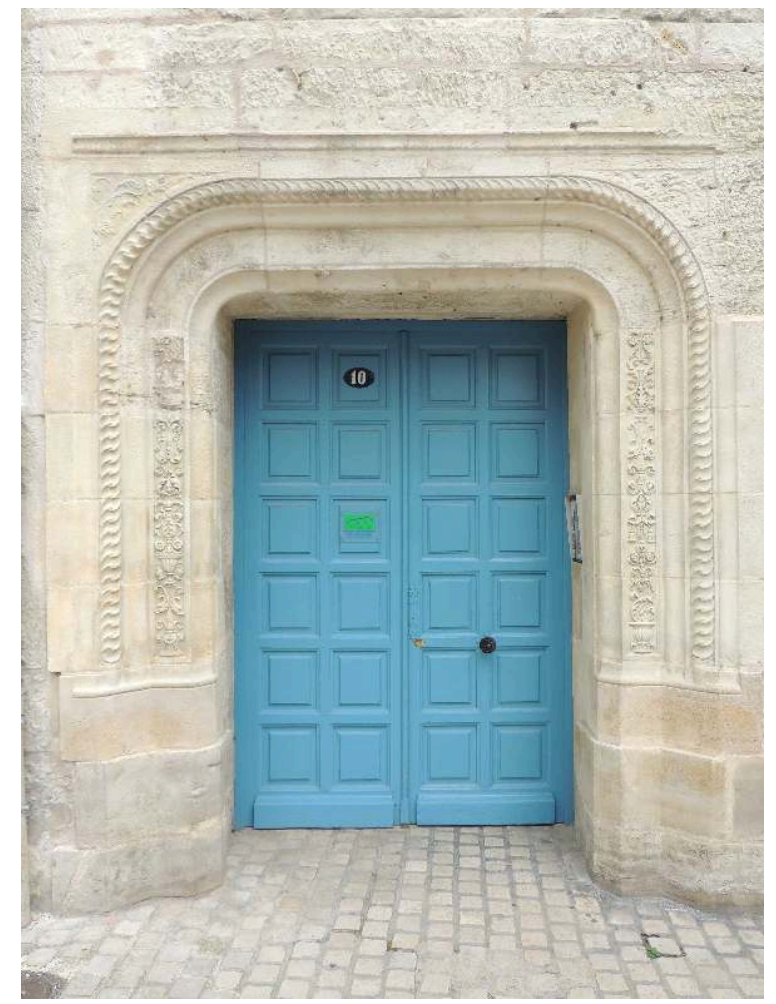

Porte du présidial, 10 place du Coderc.

(c) Valentin Coupri (service Ville d'art et d'histoire de la Ville de Périgueux). 


\section{Prisons}

33 Les prisons publiques de Périgueux furent liées, dès l'origine, à l'existence même de la maison du Consulat qui figurait chaque année, pour son entretien, dans les registres des comptes de la Ville. Le droit pour le Puy-Saint-Front d'avoir une prison lui appartenant fut reconnu officiellement en 1266 par le sénéchal de Périgord pour le roi de France.

Chaque pouvoir avait sa justice, le consulat avait la sienne et donc aussi sa prison, élément important dans l'ensemble de ses bâtiments. Elle se trouvait dans la tour d'où quelques prisonniers réussirent néanmoins à s'évader. La plupart des travaux d'entretien de la prison consistaient à renforcer les fermetures ou à réparer les dégâts commis par les prisonniers lors de leur évasion. Des textes d'archives permettent de localiser cette prison « en la tour du Consulat».

En 1407-1408, on mentionne la présence et l'entretien de cinq prisonniers. Le récit d'une évasion au XVII siècle permet de situer le local dans un étage élevé. En effet, durant la nuit précédant la Saint-Thomas, en 1627, deux prisonniers s'évadèrent " par les moyens des cordes de la grande cloche du Consulat ».

En 1636, la maison de la Ville et ses dépendances, place du Coderc, furent reconstruites par l'architecte lorrain Nicolas Rambourg (vers 1559-1649), et par Blaise Bouin.

On sait grâce aux procès-verbaux d'enquête dressés à la suite des évasions comment se présentait au XVII ${ }^{\mathrm{e}}$ siècle le local affecté aux prisons. Il comportait un guichet à l'entrée, deux portes doubles au bout d'un couloir, un cachot dont le sol était "pavé de quartiers » au rez-de-chaussée; au premier étage, un autre cachot, au-dessus du précédent, au second étage, la chambre du geôlier et une grande salle réservée aux hommes puis à gauche, dans une tour, une chambre pour les femmes, une garde-robe et une autre salle au-dessus de la salle des consuls. La situation des prisons, imbriquées dans l'hôtel de ville, favorisait les évasions. Les locaux se dégradèrent, même après la reconstruction. Le 28 novembre 1653, «Messieurs de la Cour présidiale demandent de faire une porte sur le haut du degré des prisons pour entrer dans la salle de la Cour présidiale, la galerie par laquelle on allait dans ladite salle de l'audience ayant été démolie par la garnison du prince de Condé12 ». Par arrêt du parlement de Bordeaux, le 23 août 1691, une visite fut effectuée : il fut constaté que les murs extérieurs étaient mal joints, que les poutres et planchers menaçaient ruine. Dans la pièce qui se situait au-dessus de la salle des audiences, les lambris étaient rompus. Début XVIII siècle, deux visites de pure forme furent effectuées les 18 juillet 1725 et 3 mai 1727 par les commissaires du présidial qui vérifièrent surtout les registres d'écrou. On dénombrait neuf prisonniers en 1725, treize en 1727. Le geôlier en fonction montra aux magistrats le mauvais état du cachot supérieur et la situation encore pire du cachot inférieur, décarrelé et hors d'usage. Trente ans plus tard, la municipalité voulut doter les prisons d'une chambre pour les femmes, en déblayant un terrain situé au nord des bâtiments de l'hôtel de ville pour réaliser cette construction. Le projet resta sans suite, tout comme celui de faire construire hors de la ville un ensemble qui aurait regroupé l'auditoire de justice et les prisons. Les délibérations municipales stipulent «des dépenses ruineuses » qui ne pourraient être prises en charge par la Ville et devraient incomber à toute la Guyenne plutôt qu'à la seule commune de Périgueux. L'état se dégrade de plus en plus, si bien que les évasions se multiplièrent. La situation empira 
au point que le ministre de l'Intérieur, François-Emmanuel Guichard, comte de Priest, informa les administrateurs du département « que la maison de justice de Périgueux est dans un tel état que l'humanité et la justice y sont outragées chaque jour ". Il dressait un tableau très pessimiste et demanda que l'on recherche un local pour une maison d'arrêt distincte de la maison de justice. Une prison provisoire fut installée à SaintFront en novembre 1799. Onze détenus y logeaient alors que les cent neuf autres s'entassaient au Coderc.

De nombreux décès et maladies incitèrent le préfet Léonard-Philippe Rivet, en vertu d'un décret du 9 avril 1811, à entreprendre des travaux d'appropriation dans l'ancien couvent des Augustins [fig. 9], bâti en 1615 à l'intérieur des fortifications, devenu bien national (actuel musée d'Art et d'Archéologie du Périgord).

\section{Figure 9}

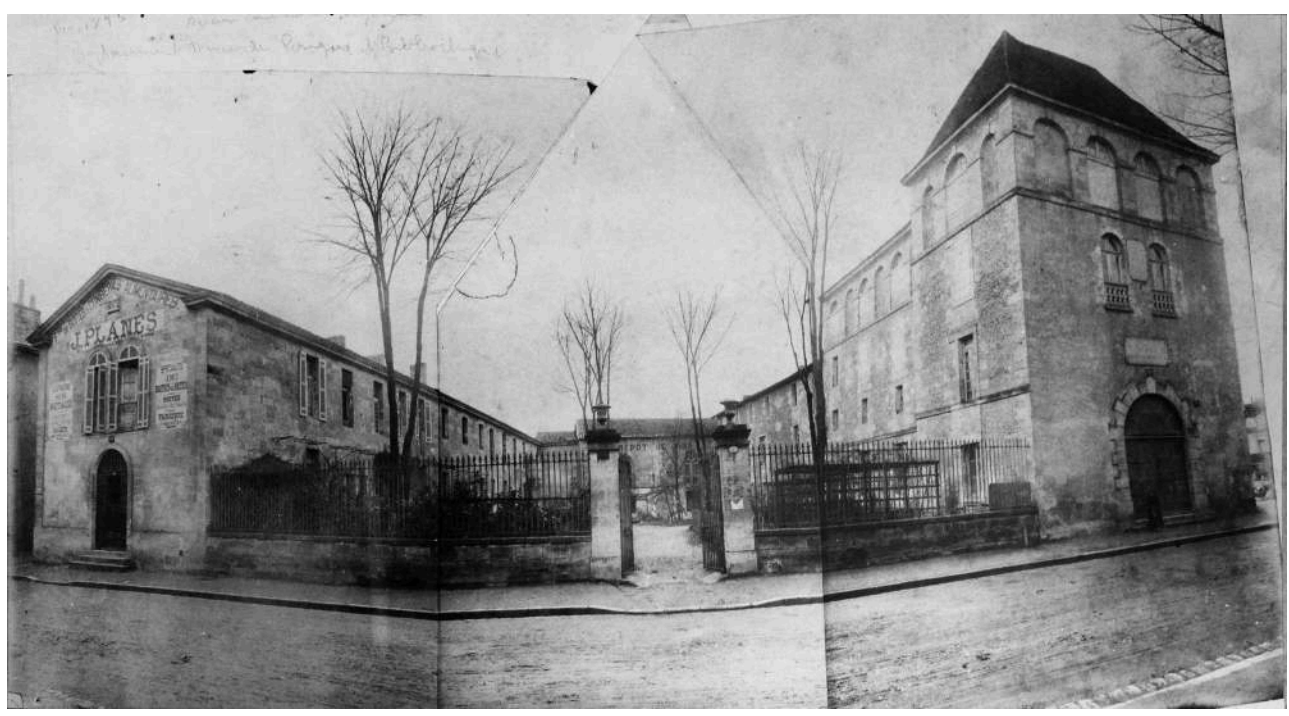

Les prisons au XIXe siècle dans l'ancien couvent des Augustins, Eugène Dorsène, 1895, photographie conservée au musée d'Art et d'Archéologie du Périgord.

Reproduction musée d'Art et d'Archéologie du Périgord.

D'abord simple prison militaire et lieu de détention des femmes à partir du 23 mai 1817 . Des travaux furent entrepris au couvent des Augustins en 1825, avec la construction, le long de la rue des Augustins, d'un corps de bâtiment destiné à mettre les prévenus au secret et à servir d'infirmerie pour les hommes. La prison fut maintenue dans le couvent des Augustins jusqu'en 1862, date de son transfert place Belleyme [fig. 10]. 
Figure 10

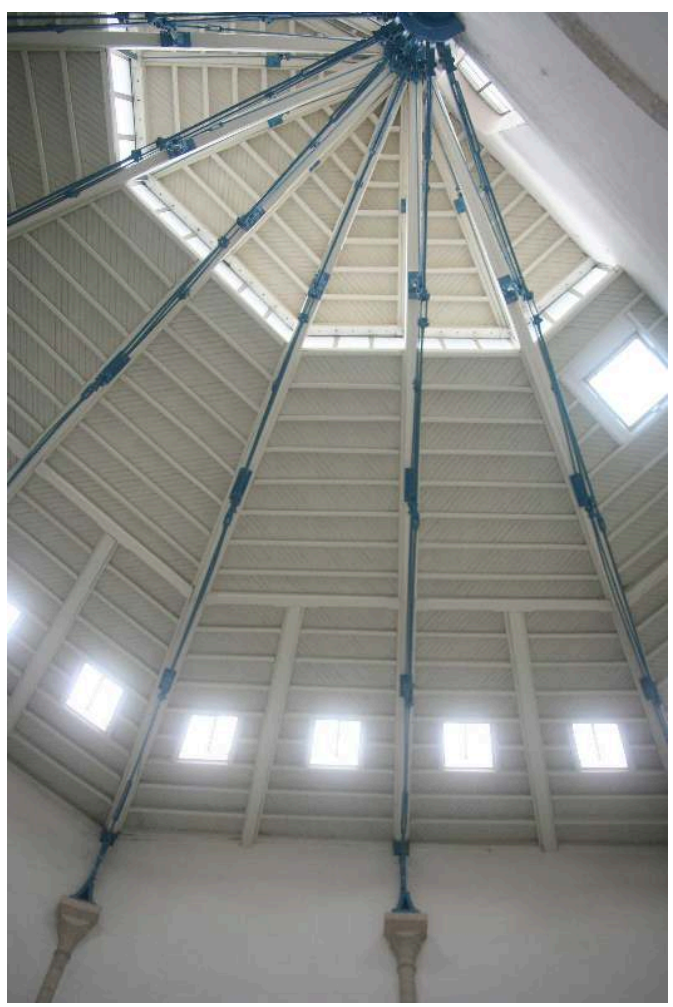

Charpente métallique « à la Eiffel » de la grande salle de la maison d'arrêt de Périgueux.

(c) Martine Balout (service Ville d'art et d'histoire de la Ville de Périgueux). l'entreprise Collin et Mouchette. Cette prison fut inaugurée le 16 octobre 1862, et le jour même les détenus y furent transférés depuis le couvent des Augustins. Elle est implantée à l'ouest de la rue Combe des Dames et s'inscrit dans un rectangle de $93 \mathrm{~m}$ sur 86, délimité par un double mur d'enceinte. Le bâtiment d'entrée est percé d'une porte centrale en arc brisé. Il se compose de trois niveaux dont les premiers sont éclairés par de simples fentes de jour, les fenêtres n'apparaissent qu'au second étage. Le porche donne accès à une cour où s'élève un édifice bâti sur deux niveaux qui abrite les locaux administratifs, le logement du gardien ainsi que l'infirmerie. Cinq bâtiments rayonnent depuis l'édifice central. Une magnifique charpente métallique «à la Eiffel », couronne au centre une grande salle polygonale.

\section{Palais de justice}

Dès le XII ${ }^{\mathrm{e}}$ siècle, le consulat possédait déjà une cour de justice, place du Coderc, à l'emplacement des halles actuelles. Cette cour était appelée simplement « fay mi drech » rapportent les archives, « faites-moi droit »!

Le 11 octobre 1800, le premier préfet du département de la Dordogne, Léonard-Philippe Rivet, loua la maison Bethou, 10 place du Coderc, en face de la maison de ville, pour y installer les tribunaux civil et criminel de la Dordogne, qui y fonctionnèrent jusqu'en janvier 1839. 
Un plan dressé en 1798 par l'ingénieur Olivier Duvaucelle montre une salle de séances, la chambre du Conseil, le greffe, le cabinet, le dépôt de papiers, le parquet. Cependant les lieux étaient trop exigus.

En 1810, dix longues années après, pourrait-on dire, notamment pour les nouveaux acquéreurs de la maison B qui, lassés d'attendre, finirent par demander aux magistrats le $1^{\text {er }}$ janvier 1839 de quitter les lieux sous huitaine. « On voit alors arriver le parquet du procureur du roi et le greffe, avec leur personnel, suivis de leurs archives et de leurs dossiers. » La première audience civile eut finalement lieu le 11 janvier 1839 et la première affaire d'assises le 14 janvier suivant. Enfin, tout était désormais en place.

Le préfet Constant Marie Huchet de Cintré demanda à l'architecte de la Ville, AlexisHonoré Roché (1757-1828), un projet de palais de justice [fig. 11], comme le souhaitait le régime de l'époque. L'architecte, qualifié de "talentueux mais sans chef-d'œuvre", d'un âge avancé, proposa un bâtiment face aux allées de Tourny, près des nouvelles prisons, sur l'emplacement du dernier couvent des Augustins.

Figure 11

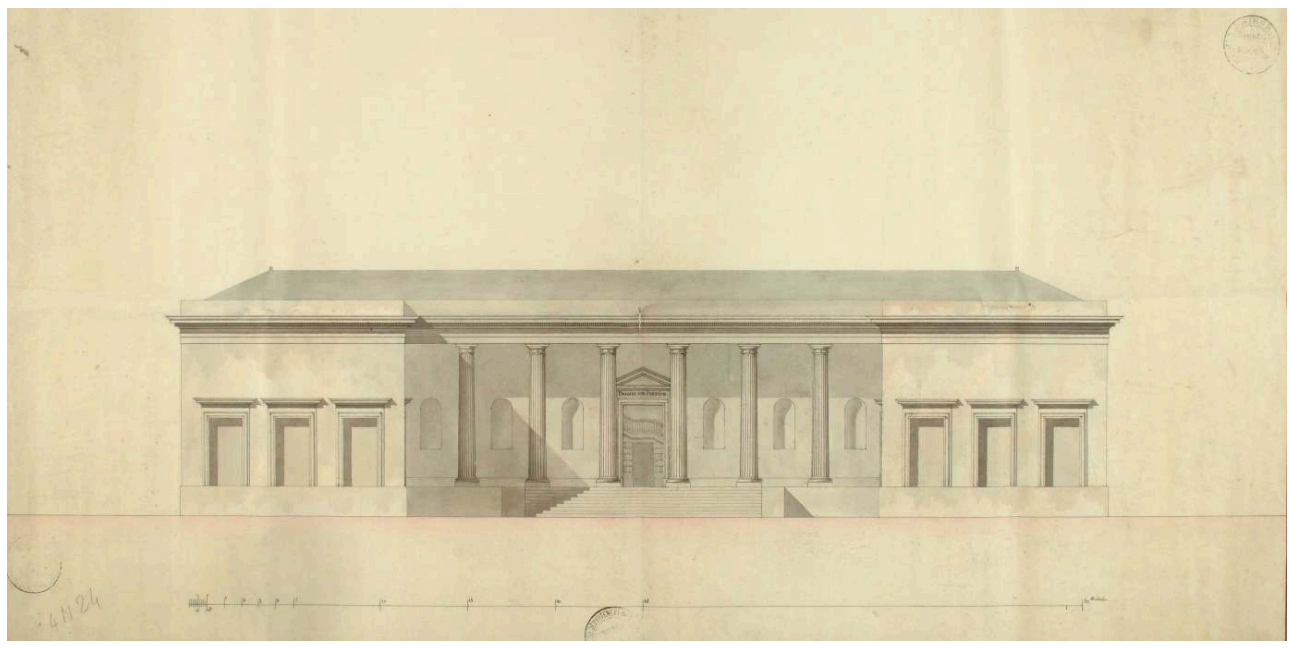

Projet d'un palais de justice à Périgueux, Alexis-Honoré Roché, 15 mai 1821, conservé aux archives départementales de la Dordogne (4 N 24).

Reproduction archives départementales de la Dordogne.

Les plans présentent un édifice sous la forme d'un vaste rectangle comportant une cour intérieure carrée, avec en façade un péristyle à six colonnes doriques cannelées à chapiteaux romains, servant de salle des pas perdus et reliant les deux ailes en retour d'angle. La construction ne possède pas le fronton triangulaire caractéristique des palais de justice de ce premier tiers du XIXe siècle. Le ministre de l'Intérieur, Jacques Joseph Guillaume Pierre, comte de Corbière approuva les plans de Roché, dont les archives départementales conservent de beaux exemples aquarellés, mais le projet n'aboutit pas. En réalité, Roché, adepte du néoclassicisme, dessina beaucoup mais aucun édifice ne sortit de terre; il ne parvint pas à convaincre les édiles. En 1826, las de subir des échecs, Alexis Roché, nommé en 1786 architecte civil puis d'ouvrage de défense comme ingénieur militaire à Bordeaux, en poste à Périgueux depuis 1819, demanda à quitter ses fonctions d'architecte départemental. Deux ans après, appelé pour diriger les travaux du grand séminaire, il meurt à la tâche dans sa chambre de l'hôtel du Chêne-Vert, à l'angle de la rue Taillefer et de la rue Chancelier-de-l'Hôpital 
où il avait pris pension. Il avait 71 ans et ce fut un architecte de 20 ans, Louis Catoire (1806-1864), qui lui succéda ! C'est Roché lui-même qui présenta au préfet ce très jeune homme sorti de l'École des beaux-arts le 5 avril 1824, que venait de lui recommander un conseiller des travaux départementaux et communaux, M. de Tournon, pour le remplacer. Catoire, premier «urbaniste » de Périgueux, mit en œuvre un outil au service de la justice.

La construction d'un palais de justice est le premier dossier confié par le préfet au jeune architecte. Pour Catoire, l'emplacement choisi par son prédécesseur manque de grandeur. Catoire veut mettre en scène le monument sur le Boulingrin (place Montaigne) [fig. 12], face à la ville encore remparée, en bordure du cours des Princes qui devient le boulevard Montaigne en 1835.

Figure 12

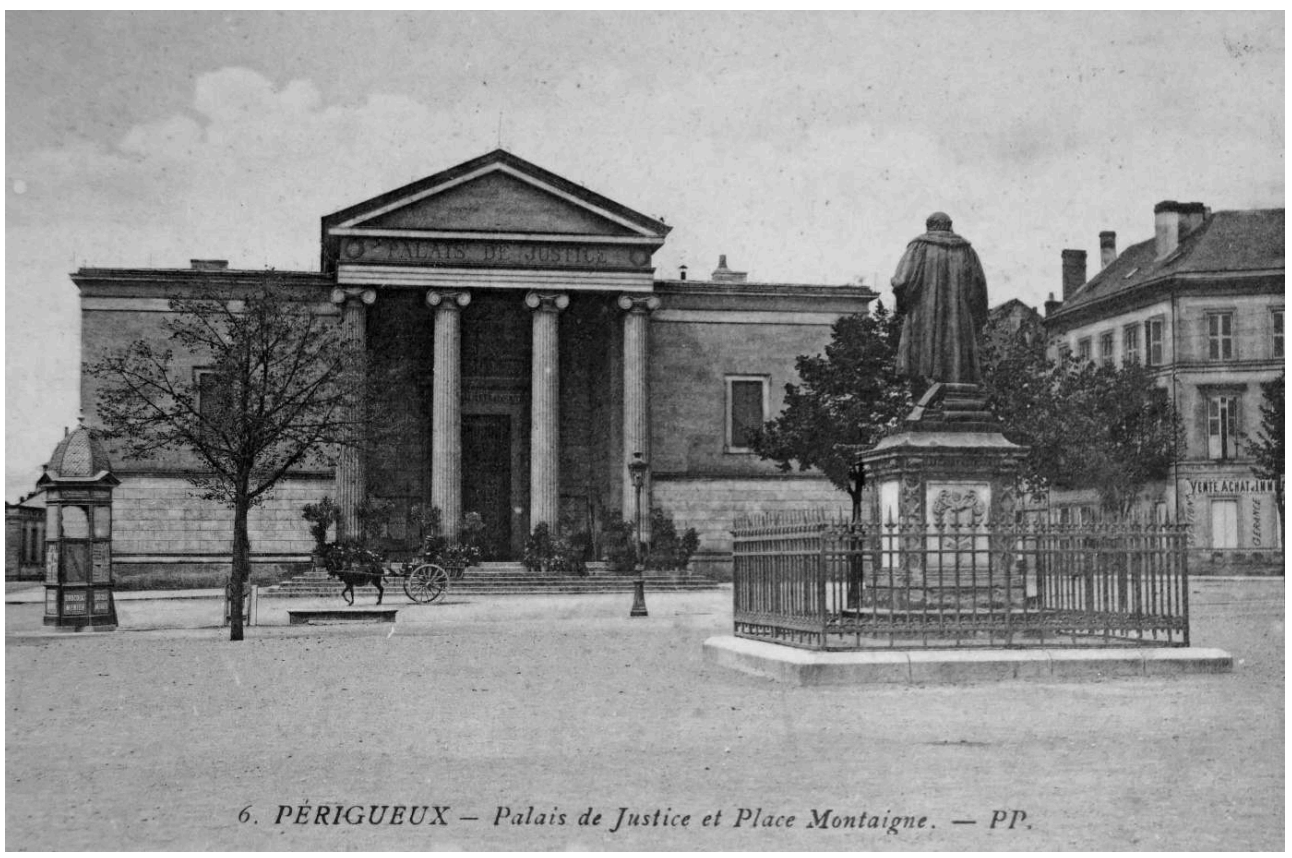

Le palais de justice et la place Montaigne, Eugène Dorsène, vers 1900, collection particulière.

Reproduction Martine Balout.

Le conseil municipal s'y oppose, avançant que serait sacrifiée la belle promenade du cours des Princes au profit d'un édifice trop imposant avec l'abattage de plusieurs arbres et des perturbations de chantier jugées insupportables pour les riverains! De surcroît, le transfert des prisonniers, boulets aux pieds depuis les prisons près des allées de Tourny paraît inconcevable. Le conseil municipal, par 21 voix, rejette ce projet. Seul le maire, M. Léger Combret de Marcillac, donne raison à Catoire. Le préfet accorde finalement la décision de construire. Le cahier des charges est présenté le 25 octobre 1827. Le devis estimatif s'élève à $215259 \mathrm{~F}$ et les honoraires de l'architecte à $5250,22 \mathrm{~F}$, en supplément de son traitement fixe.

Catoire présente ses calques au Conseil des bâtiments civils le 22 mars 1828. Son plan innovant avec un toit plat couvert en bitume pour les parties latérales est adopté sous réserves de modifications, pas toutes suivies lors du chantier! La première pierre est posée le 4 novembre 1829, jour de la fête du roi, avec un véritable cérémonial relaté par L'Écho de Vésone du samedi 7 novembre 1829. Les autorités sont réconciliées ! Un cortège 
part de l'ancienne préfecture (centre culturel François-Mitterrand) et emprunte la rue Aubergerie pour se rendre à la cathédrale et assister à l'office religieux. Catoire fait une présentation au public sur le chantier. Cette première pierre est bénite et placée sur l'ante gauche. On y insère un coffret en bois contenant trois médailles frappées pour la circonstance. Elles portent la tête du roi et la légende «Charles X roi de France et de Navarre ». Le soir, sur le chantier, un festin est offert, et l'on organise un bal à la préfecture. Le chantier dure dix ans.

50 La première affaire d'assises fut jugée le 14 janvier 1839, une histoire de coups et blessures entre deux travailleurs émigrés espagnols à Saint-Capraise-de-Lalinde ${ }^{13}$. Trois jours auparavant, le tribunal civil avait siégé avec un incident cocasse. Le panneau de chantier « On n'entre pas dans le Palais ! n'ayant pas été enlevé, un motif à cassation aurait pu être invoqué ! L'affluence était grande, très curieuse d'admirer la beauté du monument ouvert aux oracles de la justice. Catoire avait eu une vision d'urbaniste avant la lettre ; son édifice restait classique et modeste en se conformant aux standards néoclassiques enseignés par ses maîtres, avec une prise en compte du cadre urbain. Sa forme est celle d'un temple tétrastyle rectangulaire dans lequel s'inscrit un plan en croix latine. Le plan cruciforme est riche de symbolique, l'ordre juridique s'affirme par la symétrie architecturale ${ }^{14}$.

51 Le palais de justice présente d'imposantes dimensions avec une façade principale de $30 \mathrm{~m}$ sur une profondeur de $56 \mathrm{~m}$. La base est occupée par le portique et le vestibule [fig. 13], les bras constituent la salle des pas perdus. La tête est formée par la salle d'assises semi-circulaire, voûtée en cul-de-four. Le palais surplombe la rue, de six degrés d'emmarchement, imposant une ascension physique qui célèbre l'élévation spirituelle et la supériorité de la fonction judiciaire sur la vie quotidienne. Quatre colonnes cannelées élancées, d'ordre ionique, sur le modèle du temple Minerve Poliade à Athènes, participent à la mise en scène du lieu. Catoire a fait mouler les modèles exposés au British Museum. 
Figure 13

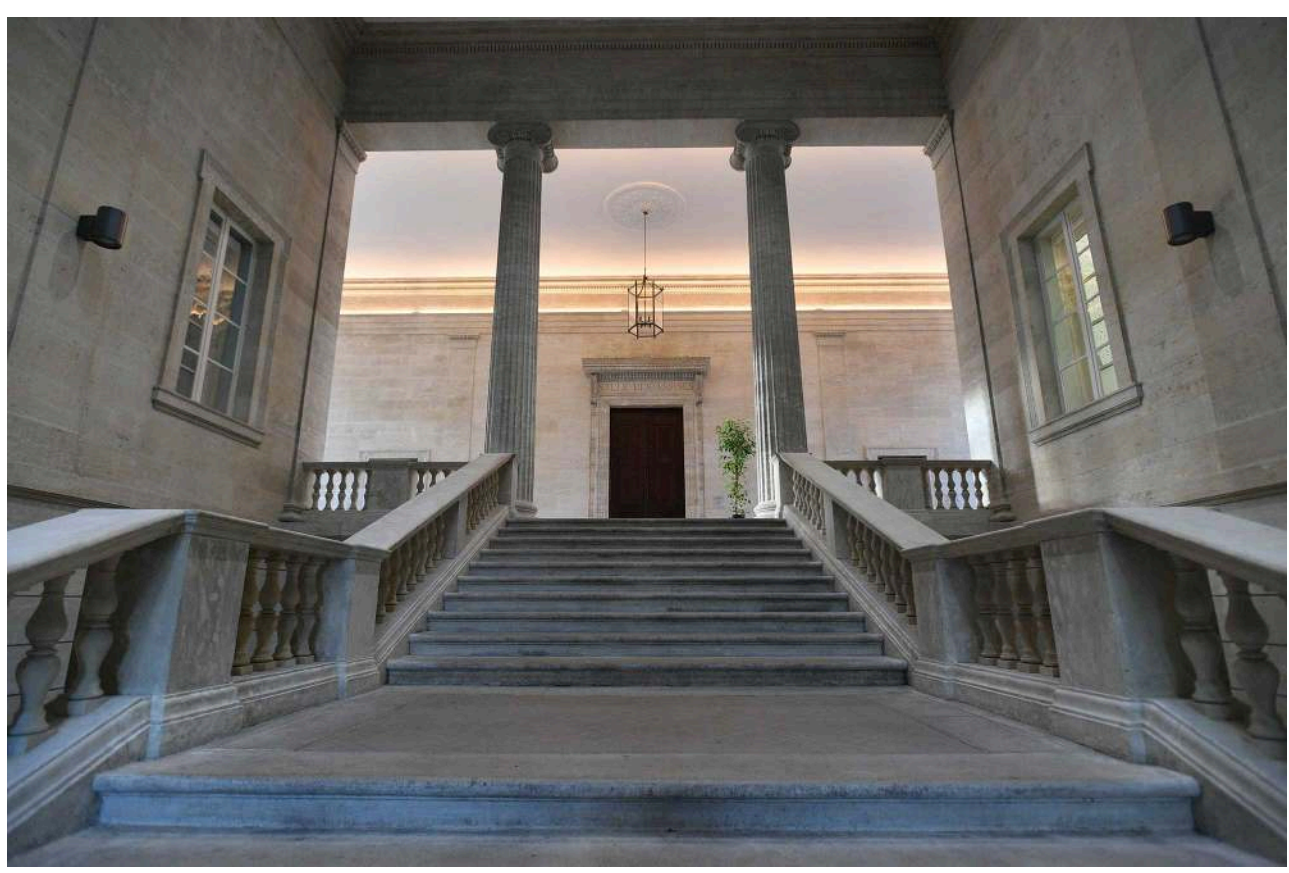

Le grand escalier, vestibule du palais de justice, 2014.

(c) Pascal Aimar / reproduction Agence pour l'immobilier de la Justice (APIJ)

Dans un élan audacieux, l'architecte a rompu avec l'emploi traditionnel des colonnes doriques pour ce type d'architecture. Les chapiteaux à deux volutes supportent l'entablement. Sur la frise, entre deux couronnes est gravée l'inscription " palais de justice ", un fronton triangulaire surmonte l'ensemble. La pierre provient des carrières locales des Izards et de Promsault. En 1835, le tribunal civil et le tribunal de commerce s'y installèrent ; le tribunal civil devint tribunal de première instance en 1852.

Dès 1841, des infiltrations d'eau de pluie apparurent. L'année suivante, les toitures furent reprises par l'architecte Bouillon qui remplaça le bitume par du plomb. La couverture reste un point faible du bâtiment.

En 1997, à l'initiative du ministère de la Culture, le palais de justice ${ }^{15}$ a été inscrit à l'inventaire supplémentaire des monuments historiques, de la façade jusqu'à la salle des pas-perdus [fig. 14]. La rénovation du palais de Justice a été confirmée le 27 janvier 2009 lorsque le garde des sceaux officialise le projet de restructuration, actant l'affectation du pôle pénal à Montaigne et du pôle civil rue Sirey. 
Figure 14

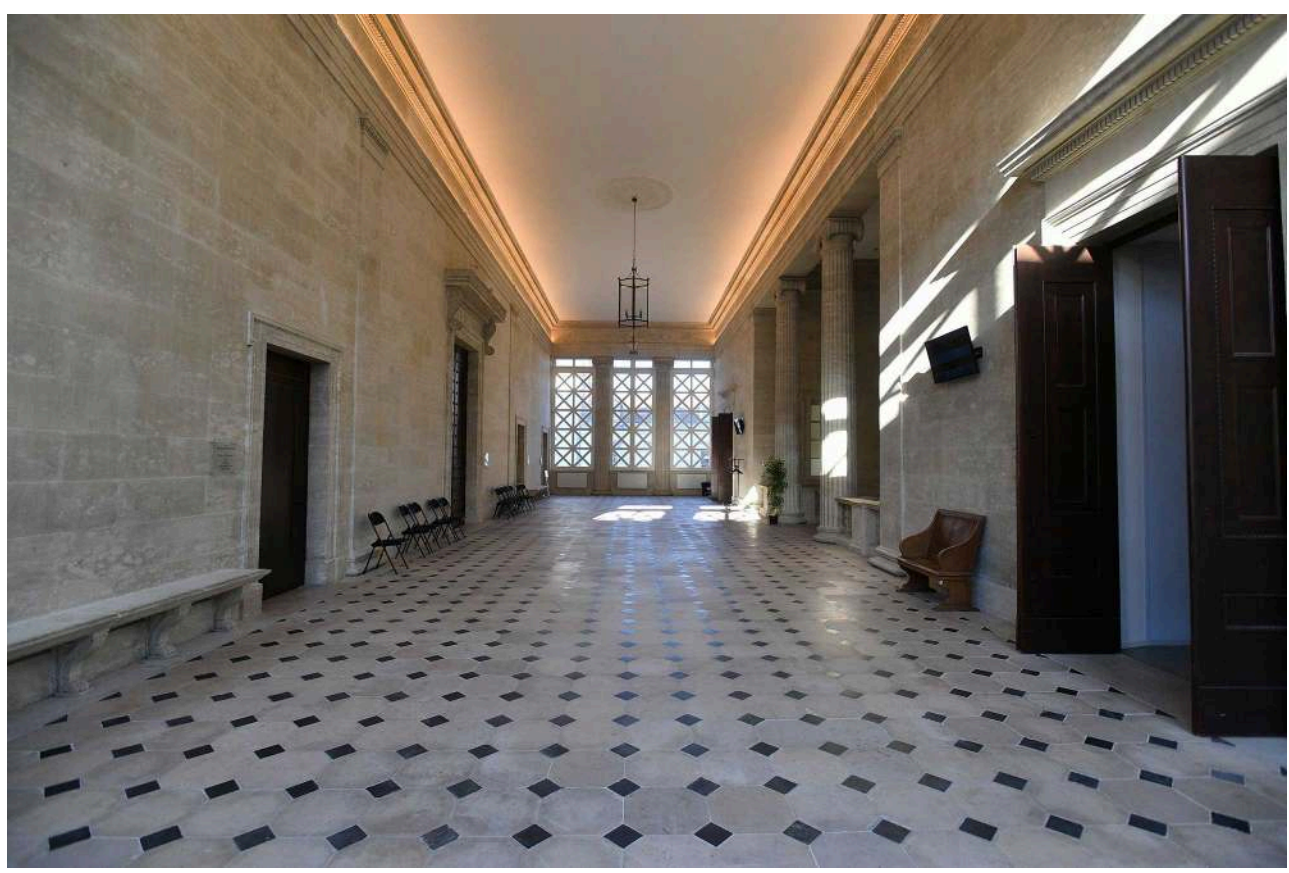

La salle des pas perdus, 2014. Depuis le 21 septembre 2019, Louis Catoire y a une plaque à son nom, dans « son » palais de justice.

(C) Pascal Aimar / reproduction Agence pour l'immobilier de la Justice (APIJ)

Les travaux de réhabilitation et de modernisation ont été confiés à l'architecte Frédéric Lafitte, de Saint-Médard-en-Jalles, assisté du bureau d'études bordelais Cetab Ingénierie et du groupement d'entreprises Vigier bâtiment. La salle d'assises a été entièrement restaurée et rééquipée, les espaces secondaires reconstruits. L'âme du palais de Catoire a toutefois été conservée.

Cent quatre-vingts ans après sa construction, "son " palais de justice demeure et les Journées européennes du patrimoine en 2019 furent l'occasion de revenir sur le parcours exceptionnel de Louis Catoire, qui a désormais une plaque à son nom dans la salle des pas perdus.

\section{NOTES}

1. VILLEPELET Ferdinand \& LAVERGNE Géraud, Inventaire sommaire des archives départementales de la Dordogne antérieures à 1790, Périgueux, imprimerie de la Dordogne, 1906-1923, introduction.

2. VERNEILH Félix de, "La chambre de justice à Périgueux en 1583-1584 ", Bulletin de la Société historique et archéologique du Périgord, tome IV, janvier-février 1877, p. 115-120, disponible en ligne https://gallica.bnf.fr/ark:/12148/bpt6k34208v [lien valide en novembre 2021].

3. HIGOUNET-NADAL Arlette \& LACOMBE Claude, «La Maison du Consulat à Périgueux. Historique, description et iconographie », Documents d'archéologie périgourdine, tome 5, 1990. 
4. VILLEPELET Robert, Histoire de la ville de Périgueux et de ses institutions municipales jusqu'au traité de Brétigny (1360), Périgueux, Imprimerie de la Dordogne, 1908, disponible en ligne https:// gallica.bnf.fr/ark:/12148/bpt6k102465x.image [lien valide en novembre 2021].

5. CHARAGEAT Martine \& VIVAS Mathieu (dir.), Les Fourches patibulaires du Moyen Âge à l'Époque moderne. Approche interdisciplinaire, actes du colloque international tenu à la Maison des sciences de l'homme d'Aquitaine, (MSHA, Pessac, 23-24 janvier 2014), [en ligne] https//criminocorpus revue org /3016 [lien valide en novembre 2021].

6. CHARAGEAT Martine \& VIVAS Mathieu (dir.), Les Fourches patibulaires du Moyen Âge à l'Époque moderne. Approche interdisciplinaire.

7. Nom donné à la guillotine.

8. HARDY Michel, "Les exécutions criminelles à Périgueux avant 1790 », Bulletin de la Société historique et archéologique du Périgord, t.XXVI, 1899, p. 216-219, disponible en ligne https:// gallica.bnf.fr/ark:/12148/bpt6k342332?rk=21459;2 [lien valide en novembre 2021].

9. DU CUMOND MARQUIS, «Lettre de Pierre de Mareuil, abbé de Brantôme, à M. de Lanssac (1554) », Bulletin de la Société historique et archéologique du Périgord, tome XXXII, 1905, p. 308-318, disponible en ligne https://gallica.bnf.fr/ark:/12148/bpt6k342394/f311.item [lien valide en novembre 2021].

10. Bulletin de la Société historique et archéologique du Périgord, tome V, 1878, p. 236-237, disponible en ligne https://gallica.bnf.fr/ark:/12148/bpt6k342096/f242.item [lien valide en novembre 2021].

11. Dujarric-Descombes Albert, «Présidial de Périgueux érigée en cour souveraine, 1590 », Bulletin de la Société historique et archéologique du Périgord, t. XXI, 1894, p. 273, disponible en ligne https://gallica.bnf.fr/ark:/12148/bpt6k342274?rk=21459;2 [lien valide en novembre 2021].

12. ROUX Chanoine J. \& MAUBoURGUET Jean, Le Livre vert de Périgueux, Périgueux, Imprimerie Ribes, tome 1, 1942, voir https://archives.gironde.fr/ark:/25651/vta3966117a6a80f772 [lien valide en novembre 2021].

Ceci est la conséquence d'une des nombreuses dégradations effectuées par les troupes du prince de Condé qui occupèrent la ville en 1651 et en sont chassées en 1653.

13. HARDY Michel, «Les exécutions criminelles à Périgueux avant 1790 », Bulletin de la Société historique et archéologique du Périgord, t.XXVI, 1899, p. 216-219, disponible en ligne https:// gallica.bnf.fr/ark:/12148/bpt6k342332?rk=21459;2 [lien valide en novembre 2021].

14. LAGRANGE Jacques, "Catoire l'urbaniste de Périgueux 1806-1864", Bulletin de la Société historique et archéologique du Périgord, t.CVII, 1980, p. 266-277, voir sur le site https:// www.shap.fr/documents/bulletins-num\%C3\%A9ris\%C3\%A9s [lien valide en novembre 2021].

15. «Palais de justice », notice $n^{\circ} P A 24000015$, base Mérimée, ministère français de la Culture, [en ligne] https://www.pop.culture.gouv.fr/notice/merimee/PA24000015 [lien valide en novembre 2021].

\section{RÉSUMÉS}

Dès le XII ${ }^{\mathrm{e}}$ siècle, le consulat de Périgueux possédait une cour de justice, place du Coderc, à l'emplacement des halles actuelles. Cette cour était intitulée simplement " fay mi drech », « faitesmoi droit ». La maison du Consulat abritait également des prisons. Les lieux d'exécution étaient alternativement une des sept collines dominant la ville et les places publiques. Au XVI ${ }^{\mathrm{e}}$ siècle, 
Périgueux bénéficia de nouvelles institutions judiciaires royales : un présidial, une cour des aides et une chambre de justice.

Le 11 octobre 1800, le premier préfet de Dordogne, Léonard-Philippe Rivet, loua une maison en face de la maison de la Ville pour y installer les tribunaux civil et criminel départementaux, qui y fonctionnèrent jusqu'en janvier 1839. Le préfet Auguste Romieu décida du transfert des prisons, jugées trop vétustes, dans l'ancien couvent des Augustins. La construction d'un palais de justice fut le premier dossier confié par son successeur, Huchet de Cintré, à un jeune architecte parisien de 20 ans, Louis Baptiste Catoire. Le choix de son emplacement, sur le boulevard Montaigne, met en scène l'édifice face à une ville remparée. La construction de ce temple de la justice se conformait aux standards néoclassiques enseignés par ses maîtres, avec une prise en compte du cadre urbain. Elle entraîna le déplacement des prisons dessinées par l'architecte Bouillon à l'ouest de la ville, place Belleyme, avec une magnifique charpente métallique « à la Eiffel ».

As early as the $12^{\text {th }}$ century, the consulate of Périgueux possessed a court of law, located place du Coderc, on the site of what is now the covered market. This court was simply called "Fay mi drech", "Assert my rights". The house of the consulate also housed prisons. Places of execution were alternatively one of the seven hills that overlooked at the city and public plazas. In the $16^{\text {th }}$ century, Périgeux benefited from new royal judicial institutions: a "présidial" (court), a "cour des aides" (court of Aids), a chamber of justice.

The $11^{\text {th }}$ October 1800, the first Prefect of Dordogne department, Léonard-Philippe Rivet, rented a house in front of the city hall in order to establish civil and criminal courts of the department, which run there until January 1839. The Prefect Aguste Romieu decided to transfer the prisons, considered too dilapidated, in the Covent of the Augustins. The building of a house of court was the first case entrusted by his successor to a young 20-year-old Parisian architect, Louis Baptiste Catoire. The choice of location for the edifice on boulevard Montaigne showcased the building facing the fortified city. The construction of this temple of justice complied with the neoclassical standards taught by his masters, taking the urban setting into consideration. It resulted in the relocation of the prisons designed by the architect Bouillon to the western part of the city, place Belleyme, with a wonderful metal frame "à la Eiffel".

\section{INDEX}

Keywords : hearing, consulate, court of assizes, Dordogne (department), justice, courthouse, heritage of justice, Périgueux, prison, court

Mots-clés : audience, consulat, cour d'assises, Dordogne, justice, palais de justice, patrimoine de la justice, Périgueux, prison, tribunal

\section{AUTEUR}

\section{MARTINE BALOUT}

Directrice du patrimoine, service Ville d'art et d'histoire, mairie de Périgueux martine.balout@perigueux.fr 